\title{
HEPARINLESS CARDIOPULMONARY BYPASS WITH ACTIVE-SITE BLOCKED FACTOR IXA: A PRELIMINARY STUDY ON THE DOG
}

Talia B. Spanier, $\mathrm{MD}^{\mathrm{a}}$

Mehmet C. Oz, $\mathrm{MD}^{\mathrm{a}}$

Oktavijan P. Minanov, MD

Ronit Simantov, $\mathrm{MD}^{\mathrm{e}}$

Walter Kisiel, $\mathrm{PhD}^{\mathrm{d}}$

David M. Stern, MD ${ }^{a, b}$

Eric A. Rose, MD

Ann Marie Schmidt, MD ${ }^{\mathrm{a}, \mathrm{c}}$
Objective: Cardiopulmonary bypass is a potent stimulus for activation of procoagulant pathways. Heparin, the traditional antithrombotic agent, however, is often associated with increased perioperative blood loss because of its multiple sites of action in the coagulation cascade and its antiplatelet and profibrinolytic effects. Furthermore, heparin-mediated immunologic reactions (that is, heparin-induced thrombocytopenia) may contraindicate its use. Cardiopulmonary bypass with a selective factor IXa inhibitor was tested to see whether it could effectively limit bypass circuit/intravascular space thrombosis while decreasing extravascular bleeding, thereby providing an alternative anticoagulant strategy when heparin may not be safely administered. Methods: Active site-blocked factor IXa, a competitive inhibitor of the assembly of factor IXa into the factor $X$ activation complex, was prepared by modification of the enzyme's active site by the use of dansyl glutamic acid-glycinearginine-chlormethylketone. Twenty mongrel dogs (five were given standard heparin/protamine; 15 were given activated site-blocked factor IXa doses ranging from 300 to $600 \mu \mathrm{g} / \mathrm{kg}$ ) underwent 1 hour of hypothermic cardiopulmonary bypass, and blood loss was monitored for 3 hours after the procedure. Results: Use of activated site-blocked factor IXa as an anticoagulant in cardiopulmonary bypass limited fibrin deposition within the extracorporeal circuit as assessed by scanning electron microscopy, comparable with the antithrombotic effect seen with heparin. In contrast to heparin, effective antithrombotic doses of activated site-blocked factor IXa significantly diminished blood loss in the thoracic cavity and in an abdominal incisional bleeding model. Conclusion: These initial studies on the dog suggest that administration of activated site-blocked factor IXa may be an effective alternative anticoagulant strategy in cardiopulmonary bypass when heparin is contraindicated, affording inhibition of intravascular/extracorporeal circuit thrombosis with enhanced hemostasis in the surgical wound. (J Thorac Cardiovasc Surg 1998;115:1179-88)
From the Departments of Surgery, ${ }^{\text {a }}$ Physiology, ${ }^{\mathrm{b}}$ and Medicine, ${ }^{\mathrm{c}}$ Columbia University College of Physicians and Surgeons, New York, N.Y., the Department of Pathology, ${ }^{\mathrm{d}}$ University of New Mexico, Albuquerque, N.M., and the Division of Hema-

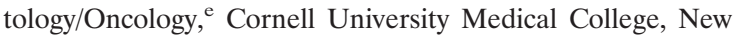
York, N.Y.

Mehmet Oz, MD, is an Irving Fellow of Columbia University.

Received for publication July 30, 1997; revisions requested Sept. 11, 1997; revisions received Dec. 18, 1997; accepted for publication Dec. 19, 1997.

Address for reprints: Talia Spanier, MD/Ann Marie Schmidt, MD, Columbia University College of Physicians and Surgeons, 630 West 168 St., P\&S 17-501, New York, NY 10032.

Copyright (C) 1998 by Mosby, Inc.

$0022-5223 / 98 \$ 5.00+0 \quad \mathbf{1 2 / 1 / 8 8 6 9 2}$ ardiopulmonary bypass (CPB) presents a substan$U$ tial prothrombotic stimulus in cardiac operations; thus its successful performance requires potent anticoagulation. ${ }^{1}$ Heparin, the traditional antithrombotic agent, however, is not without untoward side effects. Its multiple sites of action in the coagulation cascade and its profibrinolytic and antiplatelet effects contribute to an adverse bleeding diathesis and potential morbidity and death in many patients undergoing CPB. ${ }^{1-4}$ Furthermore, complications associated with the use of heparin, including heparin-induced thrombocytopenia with potential for pathologic thrombosis, also render its use contraindicated in a subset of patients. The need for pharmacologic reversal of hep- 

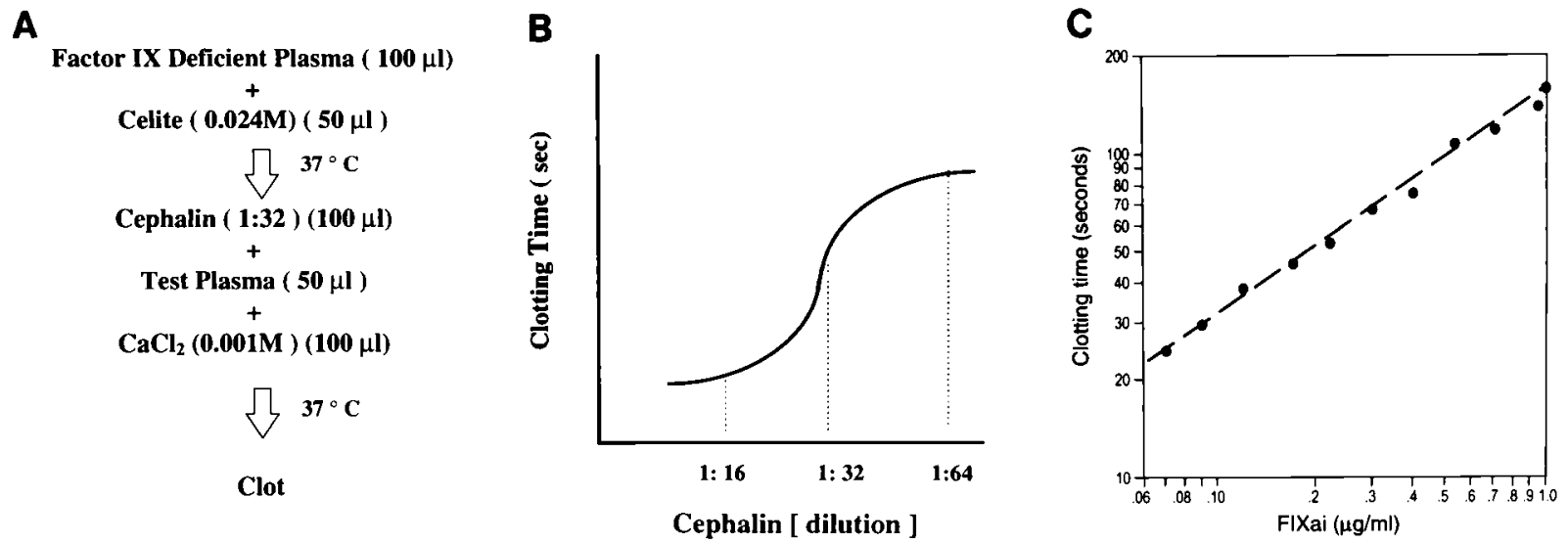

Fig. 1. MCCT. A, Assay procedure. Factor IX-deficient plasma was incubated with Celite $(0.024 \mathrm{~mol} / \mathrm{L}$ in barbital buffer $[0.05 \mathrm{~mol} / \mathrm{L}])$ in silicone-coated glass tubes for 2 minutes in a shaking water bath at $37^{\circ} \mathrm{C}$. An optimized concentration of cephalin $(1: 32 ; \mathbf{B})$ in barbital buffer $(0.05 \mathrm{~mol} / \mathrm{L})$ was added, along with control or test-dog plasma $(0.05 \mathrm{ml})$ and calcium chloride $(0.001 \mathrm{~mol} / \mathrm{L})$. Time to clot formation was then visually determined. C, Determination of the limit of detection of the MCCT was performed with different concentrations of IXai and normal dog plasma. Data were plotted as log MCCT versus log [IXai] of each value. The limit of detection in this assay is $0.06 \mu \mathrm{g} / \mathrm{ml}$.

arin effect with protamine may itself contribute to additional perioperative morbidity with the possibility of life-threatening protamine allergy and subsequent hemodynamic collapse. ${ }^{5,6}$

Although multiple strategies to perform CPB in the absence of heparin have been suggested (lowmolecular weight heparins, thrombin inhibitors, iloprost, ancrod, orgaran, or dermatan sulfate), none are routinely used in the clinics in the United States, likely because their use has been associated with such complications as potential for sensitization, cross-reactivity with heparin, profound hemodynamic instability, or excessive bleeding. ${ }^{7-13}$ Other strategies, such as addition of antifibrinolytic agents, although reducing blood loss, nevertheless do not obviate the use of heparin/protamine. ${ }^{14-16}$

In situations where the use of heparin is relatively contraindicated, we have sought an alternative anticoagulant that would selectively inhibit intravascular coagulation, resulting from the contact of circulating blood with extracorporeal membranes, filters, and tubing, while enhancing extravascular hemostasis with decreased blood loss in the surgical wound. These considerations led us to focus on the role and unique location of factor IX/IXa in the coagulation cascade.

Factor IXa expresses its procoagulant activity after incorporation into the intrinsic factor $\mathrm{X}$ activation complex, consisting of factors IXa, VIII(a) assembled on an appropriate cellular surface in the presence of calcium ions. This complex then activates factor $\mathrm{X}$, and the newly formed factor Xa then becomes integrated into the prothrombinase complex, thereby generating thrombin. In the presence of relatively low levels of tissue factor, such as that present in the intravascular space/extracorporeal circuitry during the initial phase of $\mathrm{CPB}$, inhibition of the participation of factor IX/IXa would prevent activation of coagulation mediated by both the tissue factor-factor VIIa and contact (intrinsic) pathways. However, in the presence of high levels of tissue factor, such as that present on the cut surface of the sternum and in the pericardium, the tissue factor-factor VIIa pathway would directly activate factor X, thus resulting in the generation of thrombin and clot formation in the surgical wound. ${ }^{17}$

Because selective reversible inhibitors of factor IXa have not been developed, we prepared active site-blocked factor IXa (IXai), in which the active site residues serine 376 and histidine 221 were acetylated and alkylated, respectively, with dansylGlu-Gly-Arg chloromethylketone, and used this agent as a competitive inhibitor of the assembly of factor IXa into the intrinsic factor $\mathrm{X}$ activation complex. ${ }^{18,19}$ Indeed, IXai has already been tested as a selective anticoagulant in an electric-current canine coronary thrombosis model. ${ }^{20,21}$ In those studies, compared with dogs receiving active site- 


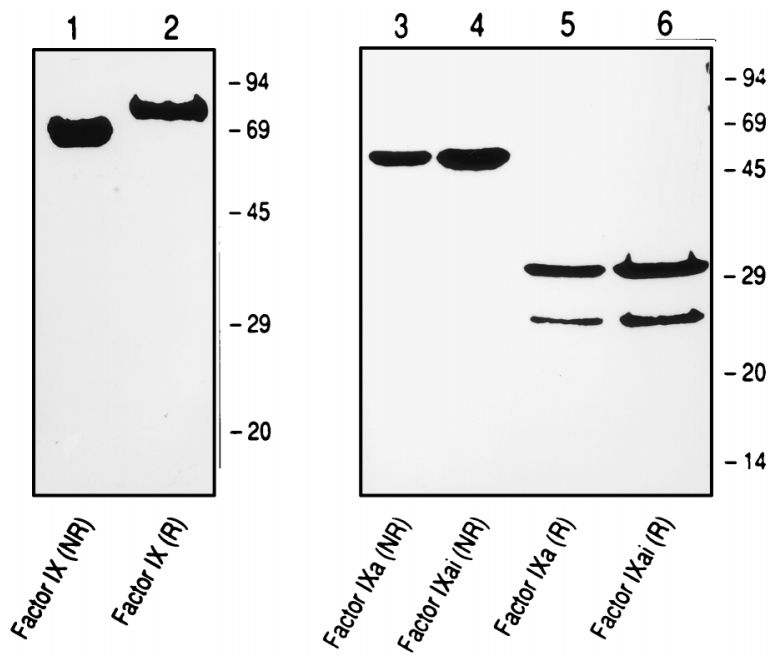

Fig. 2. Purification of factor IXai from Proplex. Factor IX was purified from Proplex and activated with factor XIa as described. IXa was then reacted with dansyl-GluGly-Arg-chloromethylketone to yield IXai. Factors IX, IXa, and IXai were run on SDS-PAGE under nonreducing or reducing conditions as indicated: Lane $1(10 \mu \mathrm{g})$; lane $2(10 \mu \mathrm{g})$; lane $3(10 \mu \mathrm{g})$; lane $4(15 \mu \mathrm{g})$; lane 5 (10 $\mu \mathrm{g})$; and lane $6(15 \mu \mathrm{g})$.

blocked Xa, dogs receiving IXai manifested inhibition of intravascular thrombosis with preservation of extravascular hemostasis (as demonstrated in an incisional abdominal wound model).

In this report, we demonstrate that administration of IXai in canine CPB results in the inhibition of intravascular thrombosis within the extracorporeal circuit, with diminished bleeding tendency within the surgical wound. These data suggest that use of IXai may be a potential alternative anticoagulant strategy in $\mathrm{CPB}$, especially in situations where the use of heparin is relatively contraindicated.

\section{Materials and methods}

Preparation and purification of IXa/IXai. Factor IXai was prepared and characterized as described in the appendix.

CPB in dogs. Twenty mongrel dogs (27 to $35 \mathrm{~kg}$ ) underwent $\mathrm{CPB}$ for 1 hour after induction of anesthesia with isoflurane and appropriate endotracheal ventilation. The heart was suspended in a pericardial cradle after median sternotomy. Anticoagulant (either factor IXai [range 300 to $600 \mu \mathrm{g} / \mathrm{kg}$ )] or heparin $300 \mathrm{IU} / \mathrm{kg}$ ) was infused intraatrially; CPB was established with cannulation of the right atrial appendage and ascending aorta (70 $\mathrm{ml} / \mathrm{kg} / \mathrm{min}, 32^{\circ} \mathrm{C}$, mean arterial pressure 55 to $70 \mathrm{~mm} \mathrm{Hg}$ ).

CPB with a roller head pump (Stockert Instrumente, Munich, Germany) primed with lactated Ringer's solution (1 liter) and a Cobe membrane lung oxygenator (Cobe
Cardiovascular, Inc., Arvada, Colo.) with sterile surgical grade Tygon tubing/filters (Norton Performance Plastics, Akron, Ohio) was maintained for 1 hour. The aorta was crossclamped, and the heart was arrested with cold crystalloid cardioplegic solution. An aortotomy was performed to simulate an aortic valve repair. Throughout the procedure a left atrial vent catheter was attached to a cardiotomy sucker. The pericardium was continuously evacuated through an additional cardiotomy sucker so as not to allow pericardial pooling of blood. The aortotomy was subsequently repaired after appropriate deairing; the heart was rewarmed, and the aortic crossclamp was released. Dogs were then weaned from CPB and decannulated.

In dogs treated with heparin, protamine $(2 \mathrm{mg} / \mathrm{kg})$ was administered intravenously at the termination of CPB. After cessation of $\mathrm{CPB}$, animals were observed for up to 3 hours to measure the extent of blood loss. At hourly intervals after bypass, blood that pooled in the pericardial and pleural spaces was suctioned, and the amount obtained was carefully quantitated and recorded. Continuous hemodynamic measurements were made and recorded before, during, and up to 3 hours after institution of CPB. One surgeon performed all of the experiments; no modifications of the operating technique were made throughout the study.

The experimental animals were divided into five groups. Group $1(n=5)$, the control group, received standard doses of heparin/protamine (300 IU/ $/ \mathrm{kg}$ and $2 \mathrm{mg} / \mathrm{kg}$, respectively). Animals treated with IXai received a single dose of IXai (group $2[n=3], 300 \mu \mathrm{g} / \mathrm{kg}$; group $3[n=3]$, $360 \mu \mathrm{g} / \mathrm{kg}$; group $4[n=6], 460 \mu \mathrm{g} / \mathrm{kg}$; and group $5[n=$ $3], 600 \mu \mathrm{g} / \mathrm{kg}$ ). No pharmacologic reversal was administered to animals treated with IXai.

All animals received humane care in compliance with the "Principles of Laboratory Animal Care" formulated by the National Society for Medical Research and the "Guide for the Care and Use of Laboratory Animals" prepared by the National Academy of Sciences and published by the National Institute of Health (NIH publication 86-23, revised 1985). This study was approved by the Columbia University Institutional Animal Review Committee and was conducted according to Columbia University policy.

Assessment of fibrin deposition in the CPB tubing and filters. At termination of $\mathrm{CPB}$, the tubing and filters were removed and subjected to analysis by scanning electron microscopy as previously described. ${ }^{22}$

Analysis of blood samples and tissue. Routine hematologic analysis was performed before the initiation of $\mathrm{CPB}$, every 15 minutes during $\mathrm{CPB}$, and then at hourly intervals after $\mathrm{CPB}$ to determine hemoglobin and hematocrit values, levels of platelets and fibrinogen, white blood cell count, prothrombin time, activated partial thromboplastin time, and activated clotting time (ACT; International Technidyne, Edison, N.J.). Celite (Celite Corporation, Quincy, Mass.) ACT was evaluated on a Hemachron model 801 (International Technidyne, Edison, N.J.). After the dogs were killed, necropsy was performed; the heart, lungs, liver, and kidney were removed, fixed in formalin $(10 \%)$, and examined by histochemistry with hematoxylin 

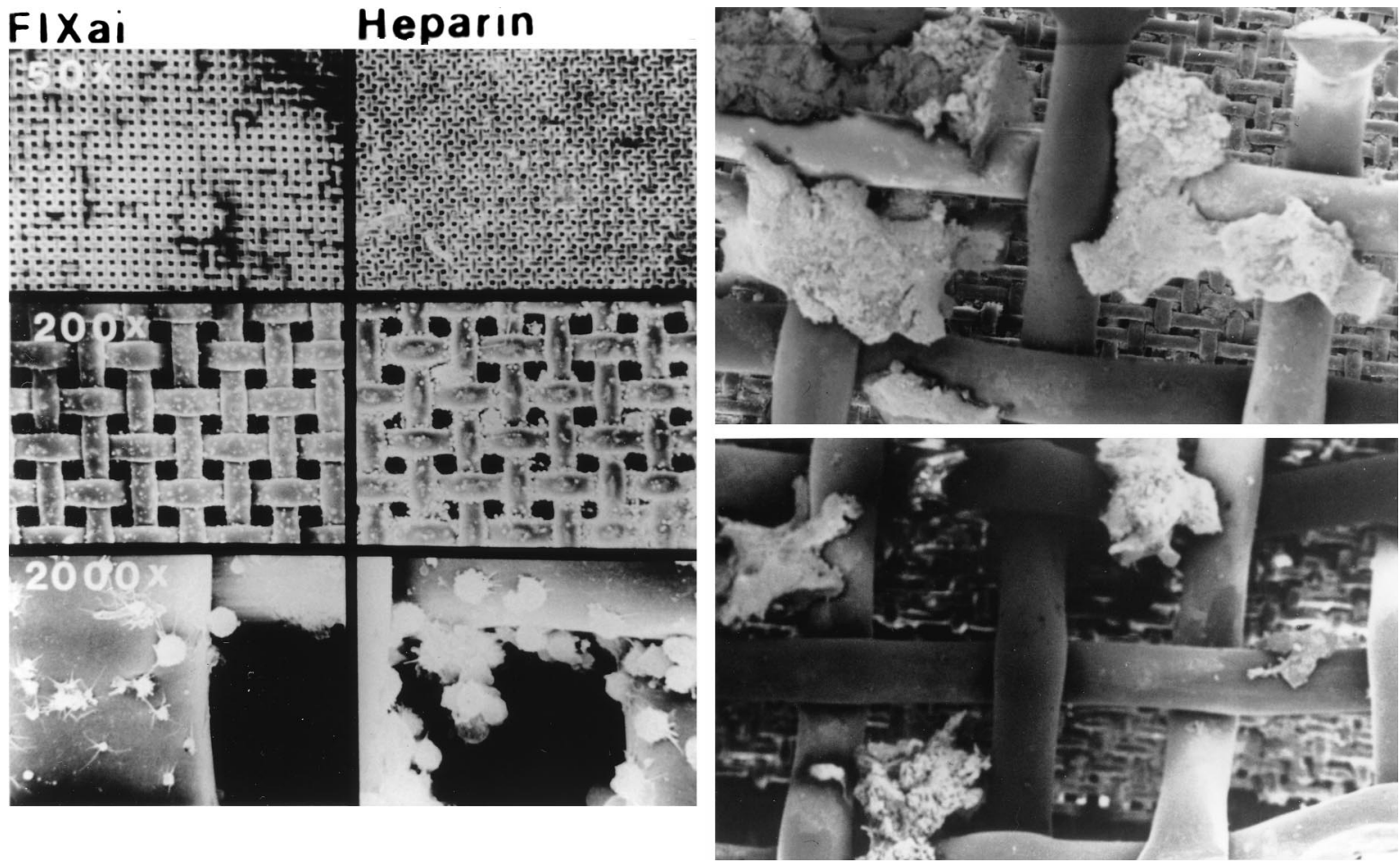

Fig. 3. Scanning electron microscopy of the CPB filters. Dogs were treated with IXai $(460 \mu \mathrm{g} / \mathrm{kg})$ or heparin (300 IU/kg/protamine $2 \mathrm{mg} / \mathrm{kg}$ ) and underwent CPB for 1 hour. At the end of CPB, the filters were removed and subjected to scanning electron microscopy at the indicated magnifications. CPB performed with IXai $(460 \mu \mathrm{g} / \mathrm{kg}$ ) was associated with similar amounts of clinically inapparent fibrin deposition, compared with heparin (left panel). At $360 \mu \mathrm{g} / \mathrm{kg}$ IXai, visible fibrin and platelet deposition was observed (right panel).

and eosin for evidence of clot/fibrin deposition and the presence of microemboli or bleeding.

Platelet aggregation studies. Platelet-rich plasma was isolated from blood collected from a normal volunteer (no aspirin intake for at least $>7$ days), and platelet aggregation was measured in response to epinephrine $(100 \mu \mathrm{m})$ or collagen $(190 \mu \mathrm{g} / \mathrm{ml})$ on a PAP 4A aggregometer (Bio/Data, Horsham, Pa.) as previously described ${ }^{23}$ in the presence of various concentrations of IXai, heparin, or a combination of IXai/heparin.

Assessment of extravascular bleeding tendency. The bleeding tendency at extravascular sites was assessed with a modified incisional bleeding time as previously described. ${ }^{20}$ Briefly, a uniform abdominal wall incision $(1 \mathrm{~cm}$ deep, $5 \mathrm{~cm}$ long) was made, and a preweighed $4 \times 4$ inch gauze was inserted for 5 minutes. The gauze was then removed and reweighed, and the weight of blood loss quantitated. Measurements were taken at baseline, immediately after institution of $\mathrm{CPB}$, and at one-half hour intervals until the animal was killed.

The modified cephalin clotting time (MCCT). To detect levels of IXai in plasma as a means of monitoring its use in $\mathrm{CPB}$, we developed a rapid, reproducible test using factor IX deficient plasma, Celite diatomaceous earth, barbital buffer, calcium chloride, cephalin, and standard dog plasma (Sigma Chemical Co., St. Louis, Mo.). Factor IX-deficient plasma $(0.1 \mathrm{ml})$ was mixed with Celite $(0.024$ $\mathrm{mol} / \mathrm{L})$ in barbital buffer $(0.05 \mathrm{~mol} / \mathrm{L})$ in silicone-coated glass tubes for 2 minutes in a shaking water bath at $37^{\circ} \mathrm{C}$ (Fig. 1, A). To this mixture was added an optimized concentration of cephalin (1:32) in barbital buffer $(0.05$ $\mathrm{mol} / \mathrm{L})$ (Fig. 1, B), control or test-dog plasma $(0.05 \mathrm{ml})$, and lastly, calcium chloride $(0.001 \mathrm{~mol} / \mathrm{L})$. Time to clot formation was then visually measured for each point. The limit of detection of IXai in this assay was $0.06 \mu \mathrm{g} / \mathrm{ml}$ (Fig. $1, C)$.

Statistical analysis. Data are expressed as the mean \pm standard error. Serial data from each group were evaluated by the repeated measures analysis of variance and then by paired $t$ test with the use of InStat 2.01 statistical analysis program (Graphpad Software, San Diego, Calif.) on a Macintosh computer (Apple Computer, Cupertino, Calif.).

\section{Results}

IXai was prepared and purified from a mixture of the human vitamin-K-dependent coagulation factors (factors II, VII, IX, and X; Proplex; Baxter 


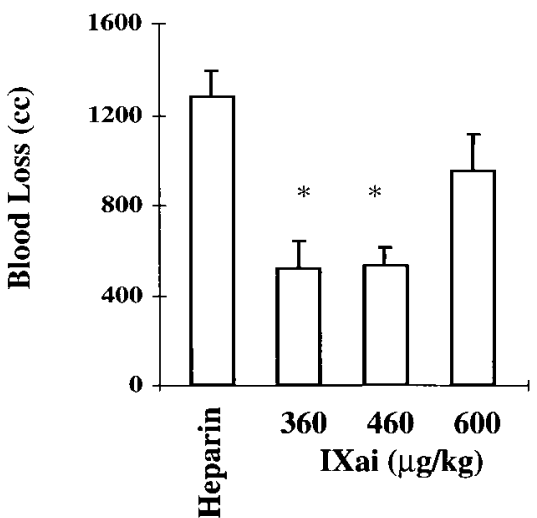

Fig. 4. Thoracic-cavity blood loss in dogs undergoing CPB. Dogs underwent CPB with either IXai (300 to 600 $\mu \mathrm{g} / \mathrm{kg}$ ) or heparin/protamine for 1 hour; dogs were then observed for 3 hours after discontinuation of CPB. At the end of the observation period, dogs receiving heparin accumulated $1275 \pm 115 \mathrm{ml}$ blood in the thoracic cavity; those dogs receiving either $360 \mu \mathrm{g} / \mathrm{kg}$ or $460 \mu \mathrm{g} / \mathrm{kg}$ IXai accumulated significantly less blood in the thoracic cavity $(530 \pm 55 \mathrm{ml}$ and $520 \pm 30 \mathrm{ml}$, respectively). At $600 \mu / \mathrm{kg}$ IXai, increased bleeding was observed in the thoracic cavity $(950 \pm 300 \mathrm{ml})$. *Indicates $p<0.05$ in dogs treated with IXai compared with heparin by analysis of variance.

Pharmaceuticals, Duarte, Calif.). Factor IX was first purified from this material and migrated as a single band on sodium dodecylsulfate-polyacrylamide gel electrophoresis (SDS-PAGE) in the absence or presence of mercaptoethanol (10\%) with an apparent relative molecular mass of approximately 68 $\mathrm{kDa}$ (Fig. 2, lanes 1 and 2, respectively). On activation of factor IX with XIa, purified factor IXa migrated as a single band on nonreduced SDSPAGE gels, with a relative molecular mass of approximately $45 \mathrm{kDa}$, and as two bands, corresponding to the heavy and light chains of factor IXa $\beta$ on reduced gels (Fig. 2, lanes 3 and 5, respectively). After inactivation with dansyl Glu-Gly-Arg chloromethylketone and extensive dialysis, the resulting factor IXai, devoid of procoagulant activity, migrated identically to IXa on SDS-PAGE (Fig. 2, lanes 4 [nonreduced] and 6 [reduced]). Subsequent to removal of detectable levels of endotoxin, IXai was then tested in canine CPB.

$\mathrm{CPB}$ was performed in 20 dogs for 1 hour at $32^{\circ} \mathrm{C}$ with standard heparin/protamine or varying doses of IXai as an anticoagulant. Compared with dogs receiving heparin $(n=5)$, dogs receiving IXai (460 $\mu \mathrm{g} / \mathrm{kg}[n=6]$ and $600 \mu \mathrm{g} / \mathrm{kg}[n=3])$ demonstrated

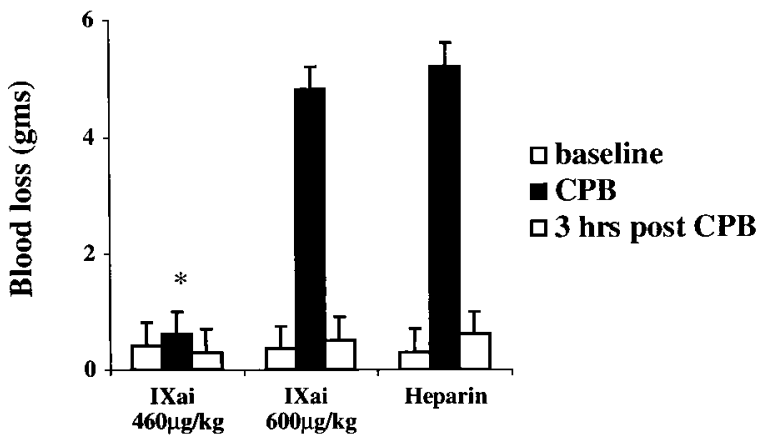

Fig. 5. Incisional wound model. To establish the effects of IXai on bleeding outside the operative field, a standardized incisional model in the abdomen was used as described earlier. At an effective antithrombotic dose of IXai $(460 \mu \mathrm{g} / \mathrm{kg})$, there was no evidence of enhanced bleeding at the time points assessed compared to baseline. In contrast, significantly increased bleeding was observed after infusion of heparin during $\mathrm{CPB}$, which returned to baseline after heparin reversal with protamine. At a dose of IXai of $600 \mu \mathrm{g} / \mathrm{kg}$, significantly increased bleeding was observed during $\mathrm{CPB}$, comparable to that seen with heparin treatment. Data are reported as means \pm standard error. *Indicates $p<0.05$ in dogs treated with IXai compared with heparin by analysis of variance.

similar hemodynamic profiles $(70 \mathrm{ml} / \mathrm{kg} / \mathrm{min}$ flow, $32^{\circ} \mathrm{C}, 55$ to $70 \mathrm{~mm} \mathrm{Hg}$ mean arterial pressure), with no evidence of increased pressures in the $\mathrm{CPB}$ tubing or circuitry at any time during the procedure. In addition, no visible clot was noted in the circuity. However, in dogs treated with the lowest dose of IXai $(300 \mu \mathrm{g} / \mathrm{kg}[n=3])$, a visible clot formed in the bypass tubing along with the development of excess line pressures, thereby necessitating premature termination of CPB. In dogs treated with IXai (360 $\mu \mathrm{g} / \mathrm{kg}[n=3])$, although a visible clot formed in the CPB circuit/tubing, CPB was successfully maintained for 1 hour with no increased line pressures. In a limited number of animals treated with the optimal antithrombotic dose of IXai (460 $\mu \mathrm{g} / \mathrm{kg} ; 6 \mathrm{dogs}$ ), $\mathrm{CPB}$ was extended to 1.5 hours to demonstrate the feasibility of the use of IXai over this time period. Similar results were found when compared to 1 hour of CPB (data not shown).

To detect fibrin or platelet deposition within the bypass circuit, the tubing and filters were removed immediately on the termination of $\mathrm{CPB}$ and analyzed by scanning electron microscopy. CPB performed with heparin or IXai $(460 \mu \mathrm{g} / \mathrm{kg}$ or 600 $\mu \mathrm{g} / \mathrm{kg}$ ) resulted in similar levels of fibrin deposition 

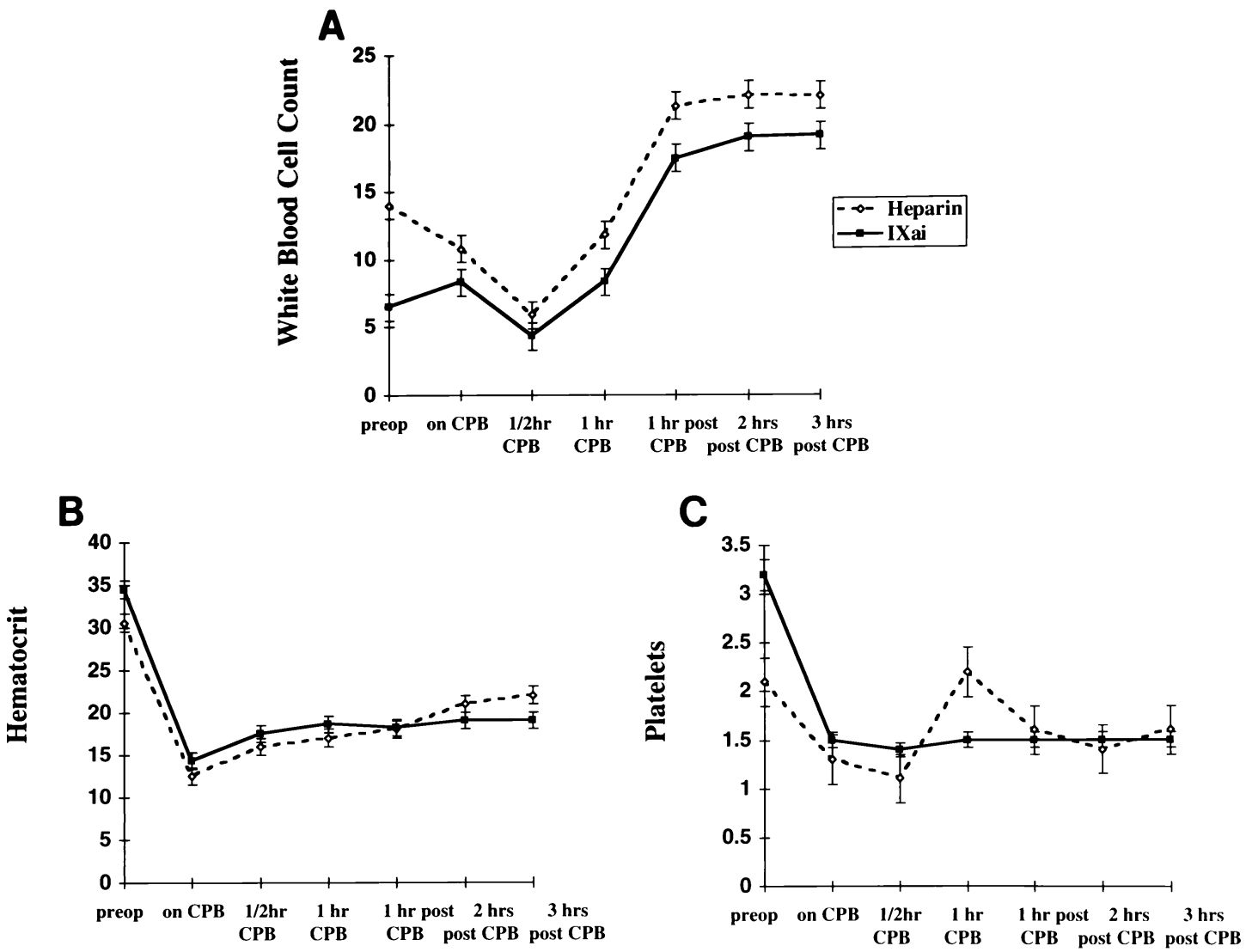

Fig. 6. Hematologic analysis. Dogs underwent CPB with either IXai (460 $\mu \mathrm{g} / \mathrm{kg})$ or heparin/protamine. At the indicated times, blood was withdrawn for analysis of white blood cell count (A), hematocrit value (B), and platelets $(\mathbf{C})$. No significant differences were observed between groups. Each group represents mean values observed in four dogs.

(Fig. 3, left panel). However, at $360 \mu \mathrm{g} / \mathrm{kg}$ IXai, significantly increased fibrin and platelet deposition was noted in the arterial filter (Fig. 3, right panel).

At an effective antithrombotic dose of IXai (460 $\mu \mathrm{g} / \mathrm{kg}$ ), no adverse effects were noted in the visceral organs. Three hours after termination of $\mathrm{CPB}$, necropsy revealed no gross or microscopic thrombosis or bleeding in the heart, lungs, liver, or kidney in animals treated with IXai compared with those receiving heparin (data not shown).

We had hypothesized that an important distinction between IXai and heparin in CPB would be the divergent effects of these agents on extravascular hemostasis. Consistent with this hypothesis, in contrast with heparin-treated animals, a hemostatic clot was observed along the cut surface of the sternum and in surgical tissue planes throughout the procedure in IXai-treated animals. Furthermore, blood loss in the thoracic cavity was diminished in dogs treated with IXai (in dogs treated with IXai, 360 $\mu \mathrm{g} / \mathrm{kg}, 520 \pm 53 \mathrm{ml}$; in dogs treated with IXai, 460 $\mu \mathrm{g} / \mathrm{kg}, 520 \pm 60 \mathrm{ml}$ ) compared with dogs receiving standard heparin/protamine $(1275 \pm 115 \mathrm{ml} ; p<$ $0.05)$. However, at $600 \mu \mathrm{g} / \mathrm{kg}$ IXai, an increased bleeding tendency was observed that was similar to that found in animals treated with heparin (950 \pm $300 \mathrm{ml} ; p=0.2$ ) (Fig. 4), suggesting a dose-dependent effect.

Further assessment of the extravascular bleeding tendency in dogs treated with IXai versus heparin was demonstrated in an abdominal incision model, essentially a modified bleeding time. On administration of IXai $(460 \mu \mathrm{g} / \mathrm{kg})$, significantly decreased bleeding was observed compared with animals treated with standard doses of heparin (Fig. 5). In contrast, treatment with $600 \mu \mathrm{g} / \mathrm{kg}$ of IXai resulted in bleeding similar to that observed with heparin (Fig. 5). Taken together, these data suggest that 


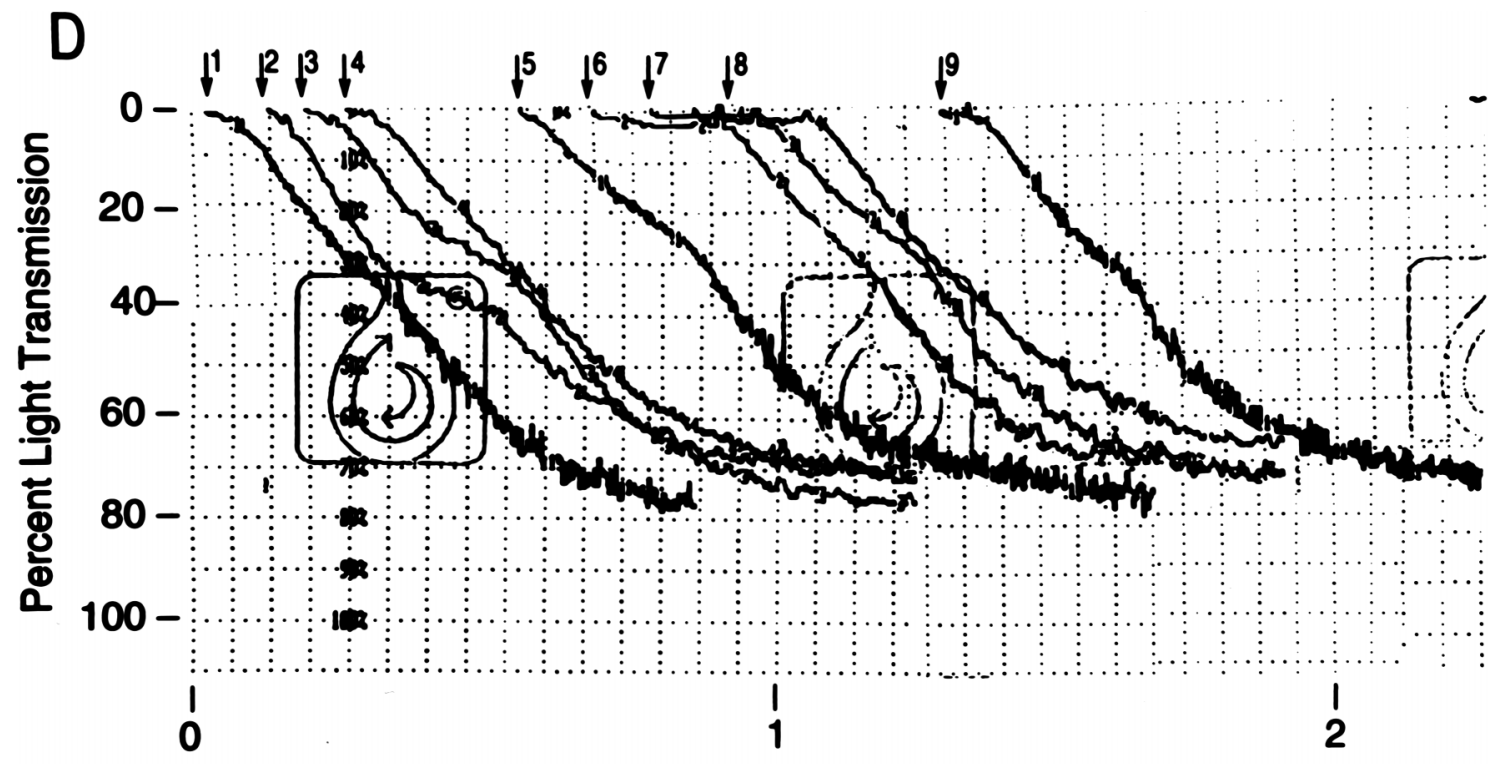

Time, minutes

Fig. 6, cont'd. D, Platelet aggregation studies as described were performed on platelet-rich plasma from normal volunteers in response to epinephrine $(100 \mu \mathrm{m})$ in the presence of various concentrations of IXai: lane 1, $5.0 \mu \mathrm{g} / \mathrm{ml}$; lane 2, $1.0 \mu \mathrm{g} / \mathrm{ml}$; lane 3, $0.8 \mu \mathrm{g} / \mathrm{ml}$; lane 4, $0.4 \mu \mathrm{g} / \mathrm{ml}$; lane 5, $0.2 \mu \mathrm{g} / \mathrm{ml}$; and lane $6,0.1$ $\mu \mathrm{g} / \mathrm{ml}$; or in the presence of IXai/heparin: lane 7, IXai $0.4 \mu \mathrm{g} / \mathrm{ml} / \mathrm{heparin} 9 \mathrm{U} / \mathrm{ml}$; or heparin alone: lane 8, $13.5 \mathrm{U} / \mathrm{ml}$; and lane 9, $9 \mathrm{U} / \mathrm{ml}$. Arrow indicates the point at which the agonist (epinephrine) was added. In all cases, primary and secondary waves of aggregation were normal.

compared with heparin, extravascular bleeding tendency is diminished in dogs treated with effective antithrombotic doses of IXai.

Use of IXai as an anticoagulant in CPB did not adversely affect routinely measured hematologic values. Compared with heparin, in dogs receiving effective antithrombotic doses of IXai $(460 \mu \mathrm{g} / \mathrm{kg})$, no untoward effects were observed on either white blood cell count or hematocrit values (Fig. 6, $A$ and $B)$. Levels of platelets were not significantly different in dogs treated with IXai or heparin, although a trend was observed toward less variability in dogs treated with IXai (Fig. 6, C).

Platelet aggregation studies performed in the presence of increasing concentrations of IXai ( 0.1 to $5.0 \mu \mathrm{g} / \mathrm{ml})$ or IXai $(0.4 \mu \mathrm{g} / \mathrm{ml})$ in combination with heparin $(9 \mathrm{U} / \mathrm{ml})$ revealed no abnormalities in primary or secondary wave of aggregation in response to either epinephrine (Fig. 6, D) or collagen (data not shown). In addition, no spontaneous aggregation was observed in the presence of IXai (0.1 to 5.0 $\mu \mathrm{g} / \mathrm{ml})$ or heparin/IXai $(9 \mathrm{U} / \mathrm{ml}$ and $0.4 \mu \mathrm{g} / \mathrm{ml}$, respectively; data not shown).

Coagulation assays revealed that compared to dogs treated with heparin, dogs treated with IXai $(460 \mu \mathrm{g} / \mathrm{kg})$ demonstrated no significant increase in prothrombin time (Fig. 7, A), activated partial thromboplastin time (Fig. 7, B), or ACT (Fig. 7, $C$ ). These findings are most likely explained by the lack of sensitivity of these assays for assessment of effective antithrombotic doses of IXai. However, to realistically use IXai in CPB, it would be important to be able to rapidly and reproducibly detect the antithrombotic activity of IXai. We therefore developed the MCCT as described earlier. Compared with preoperative values (MCCT of $21 \pm 1.2 \mathrm{sec}-$ onds), after a single dose of IXai immediately before CPB $(460 \mu \mathrm{g} / \mathrm{kg})$, MCCT rose to approximately 80 seconds through at least 1 hour of $\mathrm{CPB}$ and returned to baseline by 3 hours after CPB (Fig. 8). MCCT for heparin-treated dogs was more than 100 seconds throughout bypass, returning to baseline after protamine administration (Fig. 8). Similar results were found in dogs treated with IXai that did not undergo any surgical procedure, with a fourfold increase in MCCT after drug administration, which returned to baseline by 3 hours after administration (data not shown). 

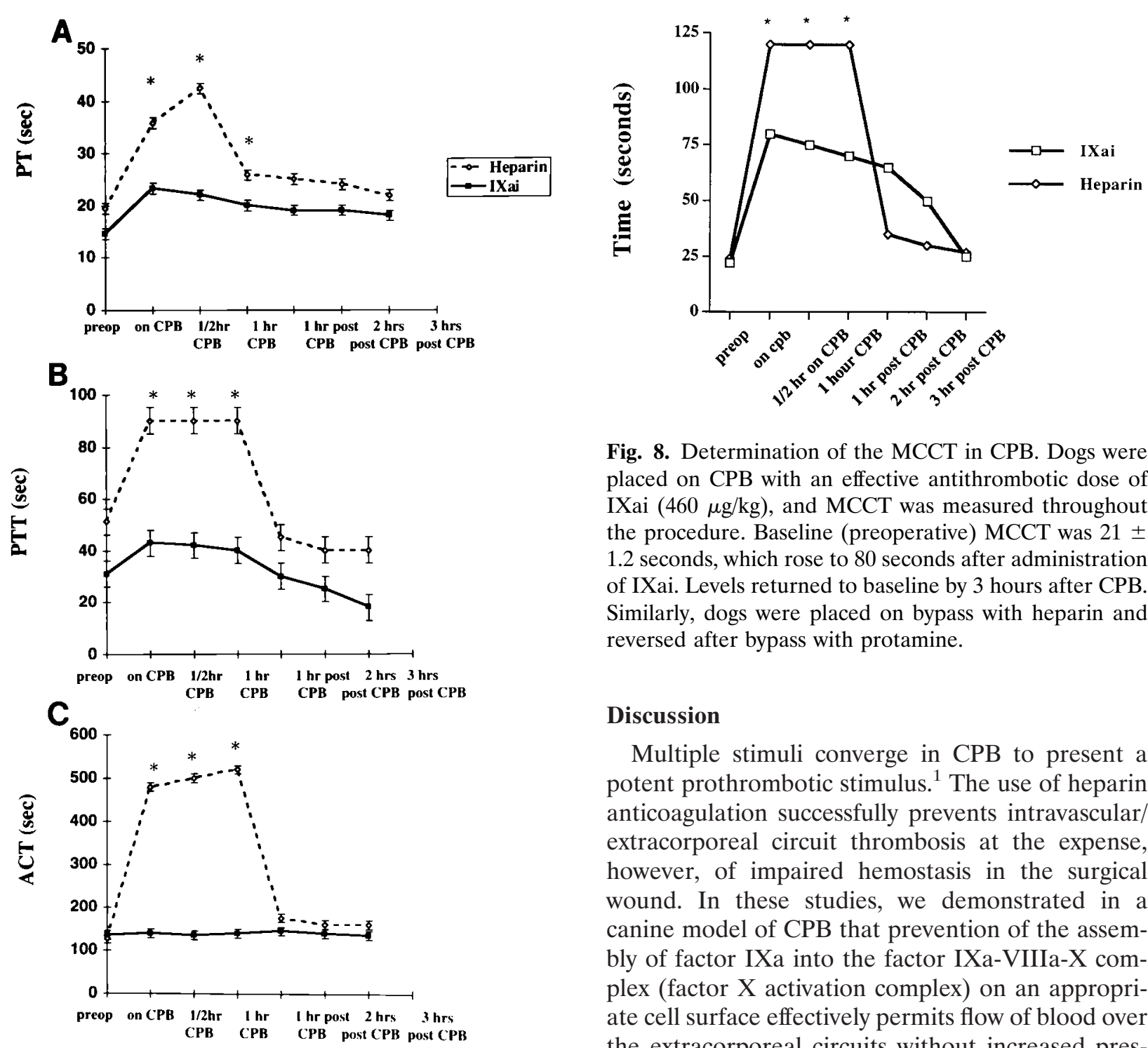

Fig. 7. Analysis of (A) prothrombin time $(P T)$, (B) activated partial thromboplastin time (PTT), and (C)ACT in dogs undergoing $\mathrm{CPB}$. Blood was withdrawn at the indicated times, and citrated plasma was prepared. PT remained control in dogs treated with IXai $(460 \mu \mathrm{g} / \mathrm{kg})$ and activated PTT was mildly elevated. In contrast, dogs treated with heparin/protamine demonstrated significant elevations of PT and activated PTT. ACT values (117 \pm 32.0 seconds at baseline in all dogs), which returned to baseline after the administration of protamine, rose to $>480$ seconds during $\mathrm{CPB}$ in the dogs treated with heparin. In contrast, in dogs treated with IXai $(460 \mu \mathrm{g} / \mathrm{kg})$, ACT did not rise significantly above baseline $(133 \pm 23.0$ seconds). * Indicates $p<0.05$ in dogs treated with IXai compared with heparin by analysis of variance.

Fig. 8. Determination of the MCCT in CPB. Dogs were placed on $\mathrm{CPB}$ with an effective antithrombotic dose of IXai $(460 \mu \mathrm{g} / \mathrm{kg})$, and MCCT was measured throughout the procedure. Baseline (preoperative) MCCT was $21 \pm$ 1.2 seconds, which rose to 80 seconds after administration of IXai. Levels returned to baseline by 3 hours after CPB. Similarly, dogs were placed on bypass with heparin and reversed after bypass with protamine.

\section{Discussion}

Multiple stimuli converge in CPB to present a potent prothrombotic stimulus. ${ }^{1}$ The use of heparin anticoagulation successfully prevents intravascular/ extracorporeal circuit thrombosis at the expense, however, of impaired hemostasis in the surgical wound. In these studies, we demonstrated in a canine model of CPB that prevention of the assembly of factor IXa into the factor IXa-VIIIa-X complex (factor $\mathrm{X}$ activation complex) on an appropriate cell surface effectively permits flow of blood over the extracorporeal circuits without increased pressures or thrombus formation within the intravascular space/extracorporeal circulation. In contrast to heparin, however, these data suggest that targeted inhibition of the participation of factor IXa in the procoagulant pathways enhances hemostasis in the surgical wound, with diminished blood loss in the thoracic cavity and in an incisional abdominal wound model.

Despite the complex set of intrinsic (contact)/ extrinsic (tissue factor)-mediated pathway interactions that together underlie the coagulopathy of $\mathrm{CPB}$, the unique position of IX/IXa in the clotting cascade may render it an ideal target for selective antithrombotic intervention in CPB. Indeed, multiple studies ${ }^{24-26}$ have indicated an important role for the contact system in CPB, as would be expected on 
the intimate contact of circulating blood with the extracorporeal circuitry: (1) reduced levels of factor $\mathrm{XII}$ indicate early activation of the clotting system in CPB; (2) levels of factor XIIa and factor XIIa activity are elevated in the plasma of patients undergoing $\mathrm{CPB}$; and (3) factor XII/XIIa become localized on tubing in the bypass circuit. An important role for the extrinsic pathway in the coagulation abnormalities observed in CPB has also been suggested: low levels of tissue factor expressed by monocytes that have adhered to the bypass circuitry (after 2 hours) may result in selective activation of IX by the tissue factor-VIIa pathway in that setting, likely to be effectively inhibited by IXai. ${ }^{27}$ Furthermore, given the progressively increased expression of endothelial tissue factor from the luminal to the adventitial side of the blood vessel, high levels of tissue factor in the surgical wound have critically limited access to the intravascular space/extracorporeal circulation, thus precluding intravascular thrombosis, while effecting tissue factor-VIIa-mediated activation of the extrinsic pathway and extravascular hemostasis, a process not affected by IXai. ${ }^{28,29}$ Indeed, recently it has been suggested that a major procoagulant perturbation in cardiac surgery/CPB is the wound itself, with high levels of tissue factor noted in the extravascular space. ${ }^{30}$

In conclusion, although we performed this procedure in a limited number of dogs, these initial data suggest that active site-blocked factor IXa might represent an alternative antithrombotic strategy in CPB, in which decreased bleeding tendency in the surgical wound results in the absence of apparent intravascular/extracorporeal circuit thrombosis. Studies in baboons are in progress to delineate site- and timedependent activation of coagulation pathways in CPB performed with IXai. In this nonhuman primate model, the use of sensitive and specific human-based reagents, which will delineate the extent of activation of coagulation and fibrinolytic pathways, will be invaluable in determining the potential efficacy of IXai as a clinical anticoagulant strategy.

We thank Mary Lynn Gaddis at Baxter Healthcare Systems (Irvine, Calif.) and Dr. Steven McCormick (New York Eye and Ear Hospital, New York, N.Y.) for performing scanning electron microscopy on the arterial filters processed after canine CPB.

\section{REFERENCES}

1. Edmunds LH Jr. Blood-surface interactions during cardiopulmonary bypass. J Card Surg 1993;8:404-10.

2. Khuri SD, Valeri CR, Loscalzo J, Weinstein MJ, Birjiniuk V,
Healey NA, et al. Heparin causes platelet dysfunction and induces fibrinolysis before cardiopulmonary bypass. Ann Thorac Surg 1995;60:1008-14.

3. Tanaka K, Takao M, Yada I, Yuasa H, Kusagawa M, Deguchi K. Alterations in coagulation and fibrinolysis associated with cardiopulmonary bypass during open heart surgery. J Cardiothorac Anesth 1989;3:181-8.

4. Pixley RA, Cassello A, DeLa Cadena RA, Kaufman N, Colman RW. Effect of heparin on the activation of factor XII and the contact system in plasma. Thromb Haemost 1991;66: 540-7.

5. Jain U. Myocardial ischemia after cardiopulmonary bypass. J Card Surg 1995:10:520-6.

6. Weiss ME, Ackinson NR Jr. Allergy to protamine. Clin Rev Allergy 1991;9:339-55.

7. Wilhelm MJ, Schmid C, Kececioglu D, Mollhoff T, Ostermann H, Scheld HH. Cardiopulmonary bypass in patients with heparin- induced thrombocytopenia using Org 10172. Ann Thorac Surg 1996;61:920-4.

8. Brister SJ, Buchanan MR. Heparinless cardiopulmonary bypass revisited: a newer strategy to avoid heparin-related bleeding using dermatan sulfate. J Cardiothorac Vasc Anesth 1995;9:317-21.

9. Riess FC, Lower C, Seelig C, Bleese N, Kormann J, MullerBerghaus $\mathrm{G}$, et al. Recombinant hirudin as a new anticoagulant during cardiac operations instead of heparin: successful for aortic valve replacement in man. J Thorac Cardiovasc Surg 1995;110:265-7.

10. Zulys VJ, Teasdale SJ, Michel ER, Skala RA, Keating SE, Viger JR, et al. Ancrod (Arvin) as an alternative to heparin anticoagulation for cardiopulmonary bypass. Anesthesiology 1989;71:870-7.

11. Bernabei A, Gikakis N, Kowalska MA, Niewiarowski S, Edmunds LH. Iloprost and echistatin protects platelets during simulated extracorporeal circulation. Ann Thorac Surg 1995;59:149-53

12. Walenga JM, Koza MJ, Park SJ, Terrell MR, Pifarre R. Evaluation of CGP 39393 as the anticoagulant in cardiopulmonary bypass operation in a dog model. Ann Thorac Surg 1994;58:1685-9.

13. Sundaram S, Gikakis N, Hack CE, Niewiarowski S, Edmunds LH, Koneti Rao A, et al. Nafamostat mesilate, a broad spectrum protease inhibitor, modulates platelet, neutrophil, and contact activation in simulated extracorporeal circulation. Thromb Haemost 1996;75:76-82.

14. Midell AI, Hallman GL, Bloodwell RD, Beall AC Jr, Yashar JJ, Cooley DA. Epsilon-aminocaproic acid for bleeding after cardiopulmonary bypass. Ann Thorac Surg 1971;11:577-82.

15. Spannagl M, Dooijewaard G, Dietrich W, Kluft C. Protection of single-chain urokinase-type plasminogen activator (scuPA) in aprotinin-treated cardiac surgical patients undergoing cardiopulmonary bypass. Thromb Haemost 1995;73:825-8.

16. Casas JI, Zuazu-Jausoro I, Mateo J, Oliver A, Litvan H, Muniz-Diaz E, et al. Aprotinin versus desmopressin for patients undergoing operations with cardiopulmonary bypass: a double-blind placebo-controlled study. J Thorac Cardiovasc Surg 1995;110:1107-7.

17. Osterud B, Rapaport SI. Activation of factor IX by the reaction product of tissue factor and factor VII: additional pathway for initiating blood coagulation. Proc Natl Acad Sci U S A 1977;74:5260-4.

18. Powers JC. Haloketone inhibitors of proteolytic enzymes. In: 
Weinstein B, editor. Chemistry and biochemistry of amino acids, peptides and proteins. Vol. 4. New York: Marcel Dekker; 1977. p. 65-178.

19. Lollar P, Fass DN. Inhibition of activated porcine factor IX by dansyl-glutamyl-glycyl-arginyl-chloromethylketone. Arch Biochem Biophys 1984;233:438-46.

20. Benedict CR, Ryan J, Wolitzky B, Ramos R, Gerlach M, Tijburg P, et al. Active site-blocked factor IXa prevents intravascular thrombus formation in the coronary vasculature without inhibiting extravascular coagulation in a canine thrombosis model. J Clin Invest 1991;88:1760-5.

21. Benedict C, Ryan J, Todd J, Kuwabara K, Tijburg P, Cartwright $\mathrm{J}$, et al. Active site-blocked factor Xa prevents intravascular thrombus formation in the coronary vasculature in parallel with inhibition of extravascular coagulation in a canine thrombosis model. Blood 1993;81:2059-66.

22. Echin P. The scanning electron microscope and its application to research. Microsc Acta 1973;73:189-204.

23. Born GVR, Cross M. The aggregation of blood platelets. J Physiol 1963;168-78.

24. Sundaram S, Courtney JM, Taggart DP, Tweddel AC, Martin W, McQuiston AM, et al. Biocompatibility of cardiopulmonary bypass: influence on blood compatibility of device type, mode of blood flow and duration of application. Int $\mathrm{J}$ Artif Organs 1994;17:118-28.

25. Vander Kamp KW, van Deveren W. Contact, coagulation and platelet interaction with heparin-treated equipment during heart surgery. Int J Artif Organs 1993;16:836-42.

26. Irvine L, Sundaram S, Courtney JM, Taggart DP, Wheatley DJ, Lowe GD. Monitoring of factor XII activity and granulocyte elastase release during cardiopulmonary bypass. ASAIO Trans 1991;37:569-71.

27. Kappelmayer J, Bernabei A, Edmunds LH Jr, Edgington TS, Colman RW. Tissue factor is expressed on monocytes during simulated extracorporeal circulation. Circ Res 1993;72:1075-81.

28. Weiss HJ, Turitto VT, Baumgartner HR, Nemerson Y, Hoffman T. Evidence for the presence of tissue factor activity on the subendothelium. Blood 1989;73:968-75.

29. Wilcox JN, Smith KM, Schwartz SM, Gordon D. Localization of tissue factor in the normal vessel wall and in the atherosclerotic plaque. Proc Natl Acad Sci USA 1989;86:2839-43.

30. Chung JH, Gikakis N, Rao AK, Drake TA, Colman RW, Edmunds LH. Pericardial blood activates the extrinsic coagulation pathway during clinical cardiopulmonary bypass. Circulation 1996;93:2014-8.
31. Braunstein KM, Noyes CM, Griffith MJ, Lundblad RL, Roberts HR. Characterization of the defect in activation of factor IX Chapel Hill by human factor XIa. J Clin Invest 1981;68:1420-6.

\section{Appendix: Preparation and purification of IXa/IXai}

Factor IXai was prepared by applying Proplex (a mixture of the human vitamin-K dependent coagulation factors [factors II, VII, IX and X] supplied by Dr. Roger Lundblad, Baxter Pharmaceuticals, Duarte, Calif.), reconstituted in TRIS-buffered saline solution (TBS; $\mathrm{pH} 7.5$ ) containing $\mathrm{CaCl}_{2}$ to a column of calcium-dependent antihuman factor IX monoclonal antibody (CaFIX-1) coupled to Affi-Gel 10 (BioRad Laboratories, Hercules, Calif.) equilibrated at $4^{\circ} \mathrm{C}$ with TBS containing $\mathrm{CaCl}_{2}(0.01$ $\mathrm{mol} / \mathrm{L})$. After sample application, the column was washed extensively with TBS containing $\mathrm{CaCl}_{2}(0.01 \mathrm{~mol} / \mathrm{L})$ and $\mathrm{NaCl}(0.5 \mathrm{~mol} / \mathrm{L})$, and factor IX was subsequently eluted in TRIS-HCl $(0.1 \mathrm{~mol} / \mathrm{L} ; \mathrm{pH} 8.0)$ containing EDTA (0.03 $\mathrm{mol} / \mathrm{L})$. Minimal residual contaminants were then removed with Q-Sepharose Fast Flow chromatography (Pharmacia Biotech, Inc., Piscataway, N.J.). Purified factor IX (Fig. 2) was then activated at $37^{\circ} \mathrm{C}$ by incubation with purified human factor XIa (1:1000 enzyme:substrate ratio $)^{31}$ in TRIS-HCl $(0.05 \mathrm{~mol} / \mathrm{L} ; \mathrm{pH} 8.0)$ containing $\mathrm{CaCl}_{2}(0.005 \mathrm{~mol} / \mathrm{L})$ for 1 hour. Factor IX (Fig. 2) was then activated in the presence of factor XIa, and the IXa thus formed was reacted with a 100-fold molar excess of dansyl-Glu-Gly-Arg chloromethylketone for 3 hours at $37^{\circ} \mathrm{C}$. Dansyl-Glu-Gly-Arg chloromethylketone was prepared in $\mathrm{HCl}(0.01 \mathrm{~mol} / \mathrm{L})$ at a concentration of approximately $5 \mathrm{mg} / \mathrm{ml}$ and incubated with factor IXa in TBS (final $\mathrm{pH}$ of the solution; 7.5). After incubation, the mixture was dialyzed overnight at $4^{\circ} \mathrm{C}$ versus 20,000 volumes of phosphate-buffered saline solution. The final product, IXai, devoid of procoagulant activity, migrated identically to IXa on SDS-PAGE (Fig. 2) and was used for experiments after filtration $(0.2 \mu \mathrm{m})$ and chromatography on DeToxi-gel columns (Pierce, Rockford, Ill.). These preparations had no detectable lipopolysaccharide at a protein concentration of 1 to $2 \mathrm{mg} / \mathrm{ml}$, with the Limulus amebocyte assay (Sigma, St. Louis, Mo.). 